Perception of Relief by Monocular Vision.

A striking example showing how any large lens can " see" in relief (see Nature, January 3, p. 224) may be demonstrated to an audience.

An electric glow-lamp is lit in an optical lantern, and the image of the filament projected on to a screen. This image is only sharp in parts.

A card with a small hole in it ( $\frac{1}{2}$ inch) is now placed close in front of the lens; this sharpens the image on the screen.

The card should now be moved backwards and forwards; the image changes in a remarkable way with every movement, showing that the lens sees the filament from a different point of view from each point of its surface.

Photographs taken with the "stop" at either side of the lens make a good stereoscopic pair.

8 Farringdon Avenue, E.C., January 19.

$$
\text { A. Е. Sмith. }
$$

THE RUWENZORI BOUNDARY DISPUTE. THE dispute which has arisen as to the ownership of the Ruwenzori Mountains between the British and the Congo State Governments is the latest example of the danger of a fixed and definite boundary agreement based on unfixed and most indefinite geographical data. So long as an elementary knowledge of geography-especially of the conditions and methods which govern geographical map makingforms no part of the educational equipment of our political staff we shall have these unscientific and clumsy disputes which may easily cost the country as much as a small war.

In this instance the agreement indicated, as the boundary between the Congo State and Uganda, " a frontier following the 3oth meridian east of Greenwich up to its intersection by the watershed between the Nile and the Congo, \&c." Presumably some sort of a map was consulted, but in 1894 , when that agreement was drawn up no map could have existed which could claim to be more than approximately accurate in respect to any position fixed relatively to the meridian of Greenwich, and in the absence of detailed topography it must have been impossible to foretell whether the demarcation of such a line was even practicable. For a political boundary to be of any value it must either be carried by some wellmarked natural feature or pass through country where artificial demarcation is possible. Consequently, of all dangerous boundary definitions that which involves a straight line through unmapped regions is perhaps the most unsafe. It might be urged that in the absence of all topography it was necessary faute de mieux to make use of an hypothetical line. In that case, treating all existing maps as a blank (which would have been the safest course), it was only necessary to express a doubt as to the finality of the arrangement whilst drafting the agreement.

In the present instance probably no one will be much the worse for an unscientific boundary muddle. A certain nervous anxiety to avoid international complications has led to our hasty abandonment of a strip of country which lies between what is now determined as the thirtieth meridian east of Greenwich and that line which was supposed to represent it when the agreement was made. The strip is about twenty-five miles in width, and the Congo officials have already taken possession and forbidden the entry of any white men unless engaged on scientific investigation. It may be a valuable strip for rubber production or it may not. Whatever it is, it has practically been given away (like many another more important field of international frontier dispute) for the want of a little scientific knowledge of the limitations of geographical definition.

NO. I944, voL. 75]

\section{THE ART OF THE LAPIDARY.}

BOOKS dealing with precious stones which have made their appearance in the past may be divided into three classes. First, works of exact science written by competent mineralogists, like the well-known treatises of Church, Max Bauer, and Kunz; secondly, treatises of an antiquarian character, of which the well-known works of C. W. King are the most conspicuous examples; and thirdly, books written from the commercial standpoint, like those of Messrs. Streeter and Emmanuel. All these classes of books treat, it is true, more or less incidentally of the lapidary's art, but the information on the subject is often second-hand and sometimes not very trustworthy.

It may be readily understood that a skilful lapidary, who is constantly handling different gems from the

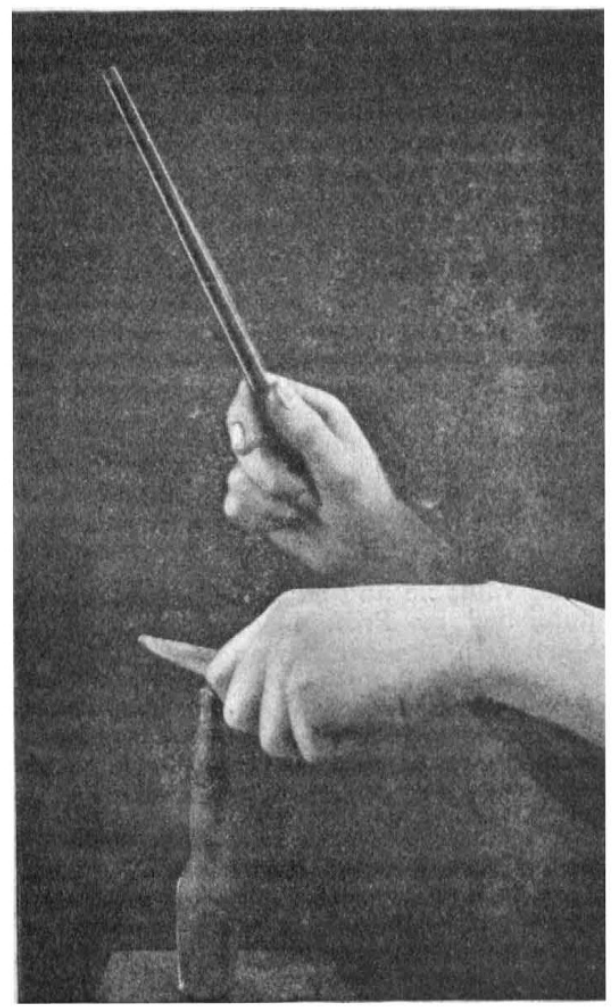

Fig. x.-D amond Cleaving. From "The Gem-Cutter's Craft."

most varied localities, must acquire an eye- and handknowledge of the objects of his craft of a very special kind; and the opinions of such men, based as they are on the results of constant observation and experience, may often be worthy of the attention of men of science. A book writtęn by a practical lapidary may thus be expected to have a peculiar interest of its own-one of a totally different character from that which attaches to the kinds which we have enumerated above; and thus it comes about that the work before us constitutes almost a new departure in the literature of precious stones.

It is only fair to the author to point out that -while justly insisting on the importance and value of the practical knowledge of gems gained by constantly handling them and by noticing their 1 “The Gem-Cutter's Craft." By Leopold Claremont. Pp. xv+296. (London: George Bell and Sons, s906.) Price iss. net. 